\title{
EMA-CE Regimen
}

National Cancer Institute

\section{Source}

National Cancer Institute. EMA-CE Regimen. NCI Thesaurus. Code C67512.

A regimen consisting of etoposide, high-dose methotrexate and dactinomycin, followed by a dose-intense etoposide and cisplatin regimen, used for the treatment of poorprognosis metastatic gestational trophoblastic tumors (GTT). 